Document downloaded from:

http://hdl.handle.net/10251/105365

This paper must be cited as:

Rojas-Buzo, S.; García-García, P.; Corma Canós, A. (2017). Remarkable Acceleration of Benzimidazole Synthesis and Cyanosilylation Reactions in a Supramolecular Solid Catalyst. ChemCatChem. 9(6):997-1004. doi:10.1002/cctc.201601407

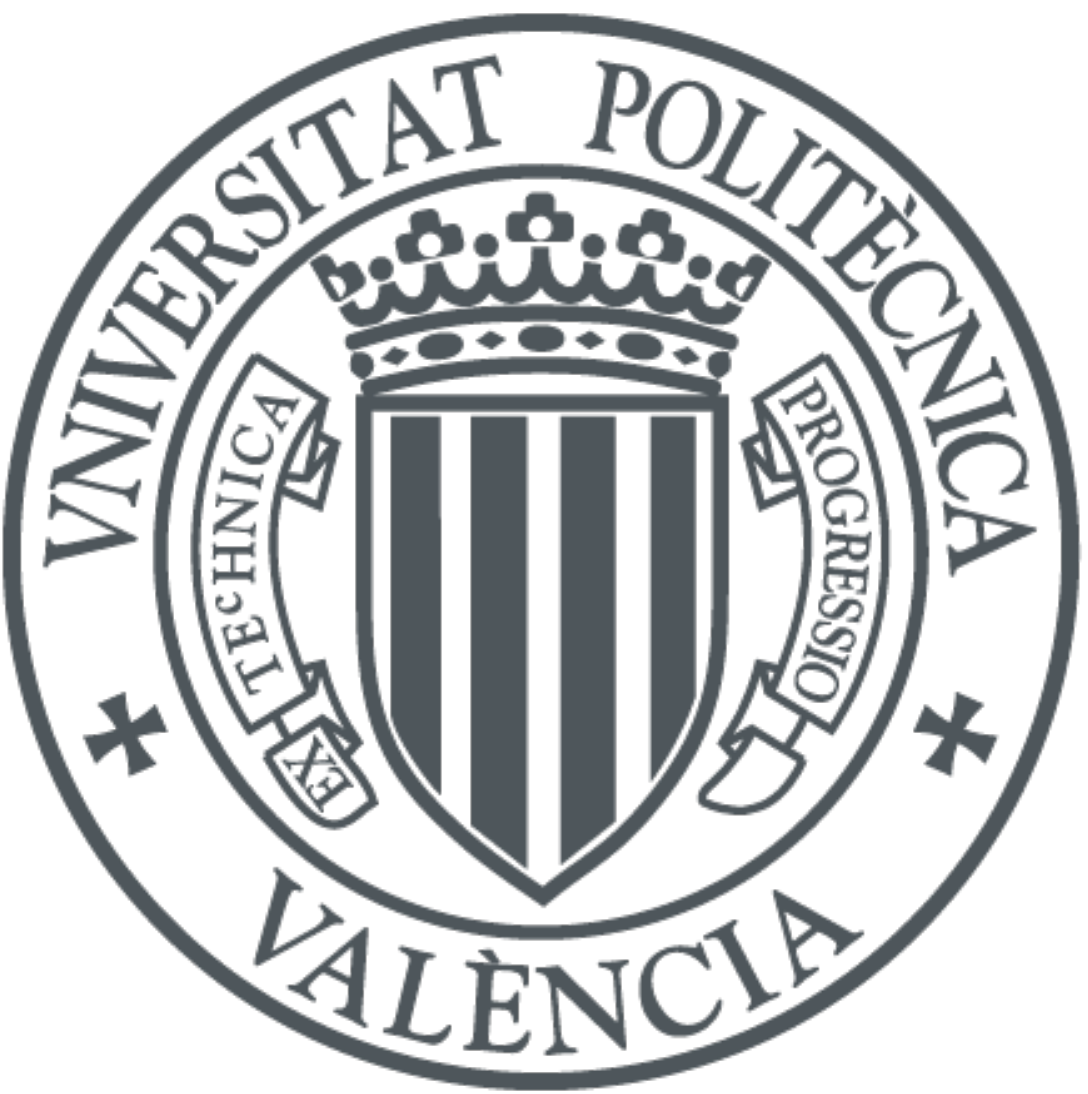

The final publication is available at

http://doi.org/10.1002/cctc.201601407

Copyright John Wiley \& Sons

Additional Information 


\title{
Remarkable Acceleration of Benzimidazoles Synthesis and Cyanosilylation Reaction in a Supramolecular Solid Catalyst
}

\author{
Sergio Rojas-Buzo, ${ }^{[a]}$ Pilar García-García, ${ }^{*[a]}$ Avelino Corma* ${ }^{\star a, b]}$
}

Dedication ((optional))

\begin{abstract}
A solid metal-organic catalyst with hydrophobic pockets and Lewis acid centers strongly accelerates the reaction rate for organic reactions. This is exemplified for the cyanosilylation of ketones and for the synthesis of benzimidazoles in where very high selectivities are obtained. The solid can be recovered and reused and its behavior approaches to a functional enzyme mimic.
\end{abstract}

\section{Introduction}

Stabilization and activation of molecules in supramolecular cage compounds is recently attracting considerable attention in the Host-Guest chemistry. ${ }^{[1]}$ The pursuit of catalysts mimicking enzyme activity is a main goal for the sake of the development of green and sustainable synthetic chemical procedures. Scientists have identify the dual role of enzymes in promoting reactions via active site performance together with many elusive and cumulative non-covalent bond interactions, resulting in excellent catalytic systems promoting the biochemical transformations in aqueous systems and under very mild reactions conditions. In this scenario, chemists have developed several synthetic host-guest systems that copy these remarkable properties such as cyclodextrins, ${ }^{[2]}$ cucurbiturils, ${ }^{[3]}$ calixarenes, ${ }^{[4]}$ carcerands, ${ }^{[5]}$ zeolites ${ }^{[6]}$ and self-assembled hosts. ${ }^{[1,7]}$ Far from the achievements already accomplished, several challenges remain such as a) the development and engineering of larger and more sophisticated host structures that can incorporate several reaction components, b) the utilization of systems that provide selectivity levels approaching those observed in natural enzymes, ${ }^{[8]}$ c) the use of truly catalytic systems wherein catalytic turnover is possible and is not inhibited by product binding ${ }^{[8]}$ and d) the possibility of a supramolecular host catalysts that could be recycled and reused. In this regard, we have recently developed a novel metalorganic hybrid supramolecular material, Al-ITQ-HB, ${ }^{[9]}$ that exhibits excellent abilities in mimicking enzyme-type catalysis. ${ }^{\left[{ }^{[a]}\right.}$ Namely, rate acceleration was demonstrated in several reactions such as Knoevenagel condensation,

\footnotetext{
[a] S. Rojas-Buzo, Dra. P. García-García, Prof. A. Corma. Instituto de Tecnología Química, UPV-CSIC, Universitat Politècnica de València-Consejo Superior de Investigaciones Científicas. Avenida de los Naranjos s/n 46022 Valencia, Spain. E-mail: pgargar@itq.upv.es, acorma@itq.upv.es.

[b] Prof. A. Corma

King Fahd University of Petroleum and Minerals, P. O. Box 989, Dhahran 31261, Saudi Arabia
}

Supporting information for this article is given via a link at the end of the document.((Please delete this text if not appropriate)) synthesis of spirooxiindoles products and asymmetric organocatalytic Michael-type reactions. Key in the design of that solid catalyst was the employment of the organic spacer 4-heptylbenzoic acid with only one carboxylate group that interacts with the inorganic metallic nodes $\left(\left[\mathrm{AlO}_{6}\right]\right)$, and also contains one hydrocarbonated tail that structurally favor the formation of lamellar and mesoscopic phases, while additionally resulting in the formation of hydrophobic pockets that probed crucial in the catalytic experiments. Here we report the remarkable ability of AI-ITQ-HB for the rate acceleration in the cyanosilylation reaction of ketones and also for the selective synthesis of benzimidazole compounds, while showing with this study that challenges a) to d) have been met.

As part of our ongoing project devoted towards the development of practical synthesis of molecules of interest in fine chemistry under a clean and green reaction profile, we have explored the possibility of synthesizing 2-substituted benzimidazoles by means of our supramolecular catalytic approach.

The benzimidazole core is an important pharmacophore in modern drug discovery. It is an integral part of various clinical medicines ${ }^{[10]}$ Benzimidazole derivatives exhibit significant activity in several therapeutic areas ${ }^{[11]}$. Additionally, they are structural subunits of many functional materials. Polybenzimidazoles $^{[12]}$ are a class of high-performance polymers which have been receiving increasing interest during the last years due to their high potential in fuel-cell technology and a number of other applications such as catalysis. Such importance from pharmacological, industrial and synthetic points of view has led to the development of several methods for the preparation of benzimidazole derivatives.

There are two general methods for the synthesis of 2-substituted benzimidazoles. The traditional method involves the condensation of o-phenylenediamines and carboxylic acids or their derivatives (nitriles, imidates or orthoesters) under harsh dehydration conditions. ${ }^{[13]}$ These procedures often require strong acidic conditions such as polyphosphoric acid or other mineral acids $^{[14]}$ sometimes combined with high temperatures (i.e. polyphosphoric acid, $180^{\circ} \mathrm{C}$ ) or the use of microwave irradiation. Another way to prepare these targets, and probably the most popular one, involves a two-step procedure with the dehydrative Schiff's base formation followed by oxidative cyclization in the same pot, using o-diaminoarenes and aldehydes as starting materials. The reported procedures for the latter protocol involve a wide spectrum of reagents such as $\ln (\mathrm{OTf})_{3},{ }^{[15]} \mathrm{Sc}(\mathrm{OTf})_{3},{ }^{[16]}$ $\mathrm{Yb}(\mathrm{OTf})_{3},{ }^{[17]} \mathrm{Sm}(\mathrm{OTf})_{3},{ }^{[18]} \mathrm{WO}_{x} / \mathrm{ZrO}_{2},{ }^{[19]} \mathrm{H}_{2} \mathrm{O}_{2} / \mathrm{HCl}^{[20]}$ Various oxidative reagents such as nitrobenzene, ${ }^{[21]} 1,4$ benzoquinone, ${ }^{[22]} \quad \mathrm{DDQ},{ }^{[23]}$ tetracyanoethylene, ${ }^{[24]}$ benzofuroxan, ${ }^{[25]} \mathrm{MnO}_{2},{ }^{[26]} \mathrm{Pb}(\mathrm{OAc}) 4{ }_{4}{ }^{[27]}$ Oxone $,{ }^{[28]} \mathrm{NaHSO}_{3},{ }^{[29]}$ $\mathrm{I}_{2},{ }^{[30]}$ sulfamic acid, ${ }^{[31]} \mathrm{IBD},{ }^{[32]} \mathrm{H}_{2} \mathrm{O}_{2} / \mathrm{HCl}^{[20]}$ and $\mathrm{Na}_{2} \mathrm{~S}_{2} \mathrm{O}_{5}{ }^{[33]}$ have been employed. However, many of these methods have some 
drawbacks such as air sensitive catalysts, the requirements of a stoichiometric or excess amount of oxidants, low yields, high reaction temperature, long reaction times, tedious work-up procedures and the occurrence of several side-reactions. Therefore, the search continues for a better catalyst for the synthesis of benzimidazoles in terms of operational simplicity, reusability, economic viability and greater selectivity.

In this paper, we report a practical, facile, and selective synthesis of 2-arylbenzimidazoles starting from ophenylenediamines and aromatic aldehydes in $\mathrm{ACN}: \mathrm{H}_{2} \mathrm{O}$ in the presence of catalytic amounts of Al-ITQ-HB at ambient temperature and with molecular oxygen as the sole "green" oxidant.

\section{Results and Discussion}

\section{Synthesis of benzimidazoles}

Recently prepared in our group, Al-ITQ-HB is a metal-organic hybrid material synthesized by the solvothermal reaction of aluminum chloride and $p$-heptylbenzoic acid in dimethylformamide. ${ }^{[9 a]}$ The solid thus obtained and owing to the specific organic linker utilized is formed by lamellar structural subdomains with octahedral aluminum units $\left(\mathrm{AlO}_{6}\right)$ separated by the hydrocarbonated tails perpendicularly located to inorganic nodes. Al-ITQ-HB presents a very weak Lewis acidity, as observed by $\mathrm{CO}$ adsorption at low temperature $(100 \mathrm{~K})$ monitored by FTIR spectroscopy. It also contains hydrophobic pockets, as created by the hydrocarbonated tails. The pore-size distribution is around 20-25 $\AA$, showcasing the mesoscopic nature of AI-ITQ-HB solid. Al-ITQ-HB has been applied as an effective catalyst that enhances the rate of a variety of condensation reactions such as Knoevenagel condensation of aromatic aldehydes with Meldrum's acid and the synthesis of spirooxiindol products as well as several enantioselective organocatalytic Michel-type reactions.

In a continuing effort to better understand the enzyme-like behavior of the hybrid Al-ITQ-HB and explore its application as catalyst for organic synthesis, we sought to investigate the ability in the synthesis of 2-substituted benzimidazoles from ophenylenediamines and aldehydes (Table 1). This synthetic procedure involves essentially two steps. Initially, Schiff's base $\mathbf{3 a}$ is formed in a dehydration step. In the second step, imine $\mathbf{3 a}$ cyclizes oxidatively to the product $\mathbf{4 a}$. Selectivity becomes an issue to consider in the procedure since 1,2-disubstituted benzimidazole $5 \mathbf{a}$ could also be formed by reaction of $3 \mathbf{3}$ with another molecule of the starting aldehyde 2a. Indeed, micellar conditions have been successfully utilized for the construction of benzimidazoles in the presence of sodium dodecyl sulfate (SDS) as catalyst. ${ }^{[34]}$ This mildly basic surface-active compound affords predominantly 1,2-disubstituted benzimidazoles of type $\mathbf{5 a}$. Nonetheless, acidic surfactant, dodecylbenzenesulfonic acid (DBSA) with the aid of the additional presence of $\mathrm{I}_{2},{ }^{[35]}$ is reported to yield preferably 2 -substituted benzimidazoles of type 4a.

We started our work with a focus on optimizing the reaction conditions. $\quad p-\mathrm{NO}_{2}$-Benzaldehyde $2 \mathrm{a}$ and 0 - phenylenediamine 1a were used in a 1:1 ratio along with $\mathrm{Al}$ ITQ-HB (30 mol\% loading), and the transformation was carried out in the presence of oxygen atmosphere $\left(\mathrm{O}_{2}\right.$ balloon, i.e. 1 bar approximately).

Table 1. Synthesis of benzimidazole $4 \mathrm{a}$ using $p-\mathrm{NO}_{2}$-benzaldehyde and 0 phenylenediamine and molecular oxygen as green oxidant. ${ }^{[a]}$.

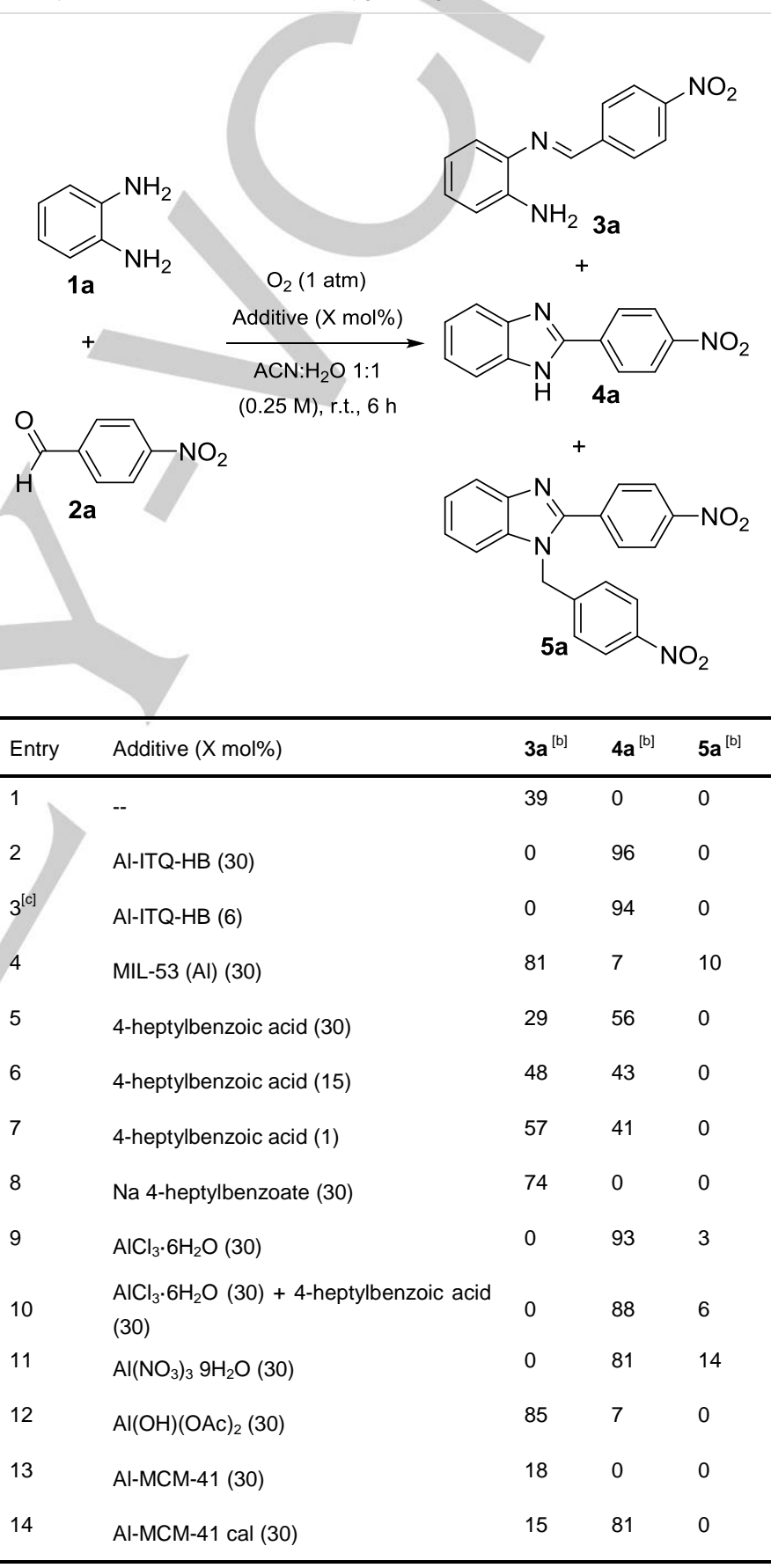

[a] Reaction conditions: o-phenylendiamine $1(0.1 \mathrm{mmol})$, aldehyde 2 (0.1 $\mathrm{mmol})$ and additive $(\mathrm{X} \mathrm{mol} \%)$ in $\mathrm{ACN}: \mathrm{H}_{2} \mathrm{O} 1: 1(0.25 \mathrm{M})$ at room temperature under $\mathrm{O}_{2}$ atmosphere for 6 hours. [b] \% Yield determined by ${ }^{1} \mathrm{H}$ NMR using trimethoxybenzene as external standard. [c] 24 hours 
First trials pointed out the influence of the solvent election in the reaction yield and selectivity towards $\mathbf{3} \mathbf{a}, \mathbf{4 a}$ or $\mathbf{5 a}$. 1,2Disubstituted benzimidazole 5 a was not formed in any of the solvents tested as determined by ${ }^{1} \mathrm{H}$ NMR of the crude reaction mixture. We found out that $A C N$ was the solvent that affords benzimidazole $\mathbf{4 a}$ in higher yield (see Supporting Information for optimization details). Combination with $\mathrm{H}_{2} \mathrm{O}$ resulted beneficial, and the desired product $\mathbf{4 a}$ was formed in $94 \%$ yield under very mild reaction conditions (neutral, room temperature) in the presence of 6 mol\% of Al-ITQ-HB, as the product easily diffuse through the mesoporous channels liberating the host to embrace another pair of reacting components (Table 1, Entry 3). Control experiment without catalyst showed barely formation of benzimidazole product 4a (Table 1, Entry 1). With the aim to determine whether hydrophobic pockets in Al-ITQ-HB play a role in the catalytic procedure, the activity of the metal-organic framework MIL$53(\mathrm{Al})$ was also tested for the synthesis of benzimidazole $\mathbf{4 a}$ MIL-53 (Al) is a 3D framework built up of infinite trans chains of corner-sharing $\mathrm{AlO}_{4}(\mathrm{OH})_{2}$ octahedra. The chains are interconnected by the 1,4-benzenedicarboxylate groups creating 1D rhombic-shaped tunnels. ${ }^{[36]}$ MIL-53 (Al) also presents Lewis acidity as observed by $\mathrm{CO}$ adsorption at low temperature $(100 \mathrm{~K})$ monitored by FTIR spectroscopy ${ }^{[9 a]}$ and its ability in sorption of several gases such as $\mathrm{O}_{2}$ among others have been reported. ${ }^{[37]}$ We found out that MIL-53 (Al) affords benzimidazole product $\mathbf{4 a}$ in low yield of $7 \%$ (Table 1 Entry 4) under otherwise identical reaction conditions. This experiment reveals the special features of Al-ITQ-HB such as the lamellar structural subdomain and the hydrophobic characteristic that could be harnessed for interesting applications such as heterogeneous catalysis.

It was found that 4-heptylbenzoic acid also promotes the transformation, a fact that was expected since we can find several reports in the literature that claim that acidic catalysts favor formation of 2-substituted benzimidazoles. ${ }^{[20,35]}$ However, we observed that 4-heptylbenzoic acid was not selective in the transformation resulting in mixtures of products, imine $\mathbf{3 a}$ and benzimidazole $\mathbf{4 a}$, in varied proportions depending on the amount of acid catalyst employed (Table 1, Entries 5-7). Micellar catalysis was also tested by using sodium 4-heptylbenzoate under otherwise similar conditions that resulted in no formation of the benzimidazole product $\mathbf{4 a}$, and only imine $\mathbf{3 a}$ was detected by ${ }^{1} \mathrm{H}$ NMR of the crude reaction mixture (Table 1, Entry 8). This study was completed with the testing of several aluminum Lewis acidic catalysts. ${ }^{[38]}$ Under the reaction conditions employed here, we found that $\mathrm{AICl}_{3} \cdot 6 \mathrm{H}_{2} \mathrm{O}$ itself or in combination with 4-heptylbenzoic acid also promote the transformation, and benzimidazole $\mathbf{4 a}$ is formed in 93 and $88 \%$ yield along with low amounts of derivative 5 a (Table 1, Entries 9 and 10) that was not detected when using the supramolecular host catalyst $\mathrm{Al}-\mathrm{ITQ}-\mathrm{HB}$. $\mathrm{Al}\left(\mathrm{NO}_{3}\right)_{3} \cdot 9 \mathrm{H}_{2} \mathrm{O}$ also promotes the transformation, although subproduct $\mathbf{5 a}$ was formed in larger amount of $14 \%$ yield (Table 1, Entry 11$)$. $\mathrm{Al}(\mathrm{OH})(\mathrm{OAc})_{2}$ appears similar to the structural building unit in AI-ITQ-HB and therefore catalytic activity was also tested for the benzimidazole synthesis (Table 1, Entry 12) that was obtained in a low yield of $7 \%$, once again evidencing the critical role of the hydrophobic property of our supramolecular host solid. To complement this study, we also tested the activity of siliceous based heterogeneous mesoporous catalysts. Therefore, Al-MCM 41 with a Si:Al ratio of 15 was employed. This material was tested in the calcined version (Table 1, Entry 14), as well as with the inclusion of the cetyltrimethylammonium bromide that it is employed in its synthesis (Table 1, Entry 13) and could possibly form hydrophobic pockets itself inside the siliceous material. While the latter did not afford the desired product $\mathbf{4 a}$, a good yield of $81 \%$ was obtained when using the calcined Al-MCM 41 . These results reveal the importance of easy accessibility to active sites in the catalytic procedure. Whereas calcined Al-MCM 41 presents a free mesoporous scaffold in where reactants and formed products can easily diffuse, the presence of cetyltrimethylammonium bromide would clog the pores and channels hindering transport of molecules to the active sites and therefore resulted in a non-appropriate catalytic material.

As to the mechanism, we speculated that the benzimidazole synthesis proceeds via activation of the aldehyde substrate by the weak Lewis acidic site in the solid (Scheme 1). The diamine then attacks the aldehyde activated by the aluminum center, resulting in the formation of Schiff's base $3 \mathbf{a}$ in a dehydration step. This transformation is always inclined toward the product 3a since the water molecule is ejected out of the hydrophobic core as soon as it is formed. In the second step, imine 3a (activated by the Lewis acidic site) cyclizes to dihydrobenzimidazole $\mathbf{A}$ that gets oxidized to the product $\mathbf{4 a}$ by the dissolved oxygen in the solvent. The weak Lewis acidity combined with the $\mathrm{O}_{2}$ sorption capacity of this type of solids ${ }^{[37]}$ should favor this oxidative cyclization step.

The reaction was followed over time (Scheme 2) by using ${ }^{1} \mathrm{H}$ NMR spectroscopy analysis. We observe that in the presence of Al-ITQ-HB, starting materials are fully converted within the first 20 minutes, to form the Schiff's base product 3a that afterwards cyclizes oxidatively to the benzimidazole $4 a$ with $\mathrm{O}_{2}$ as oxidant. The hydrophobic core of the solid along with the weak Lewis acidity facilitates the fast conversion of the starting materials to the initially formed $3 a$ product. The efficient binding of the two substrates to the hydrophobic pocket circumvents the entropic cost of the bimolecular reaction and the condensation reaction seems to be facilitated as the water molecule is ejected out of the hydrophobic core as soon as it is formed. Intramolecular cyclization then occurs to form dihydrobenzimidazol $\mathbf{A}$, while oxidation to $4 \mathbf{a}$ appeared straightforward since intermediate $\mathbf{A}$ (Scheme 1) was not detected at any stage by ${ }^{1} \mathrm{H}$ NMR spectroscopy analysis. Product $\mathbf{3 a}$ is also formed in the control experiment (no additive used) although at much lower pace achieving a conversion of $39 \%$ in the same reaction time $(6$ hours) while benzimidazole $\mathbf{4 a}$ is not detected in this case (Scheme 2). After 24 hours, the control experiment shows full conversion to products $\mathbf{3 a}$ and $\mathbf{4 a}$ in 89 and $9 \%$ yield, respectively (data shown in the Supporting Information). 


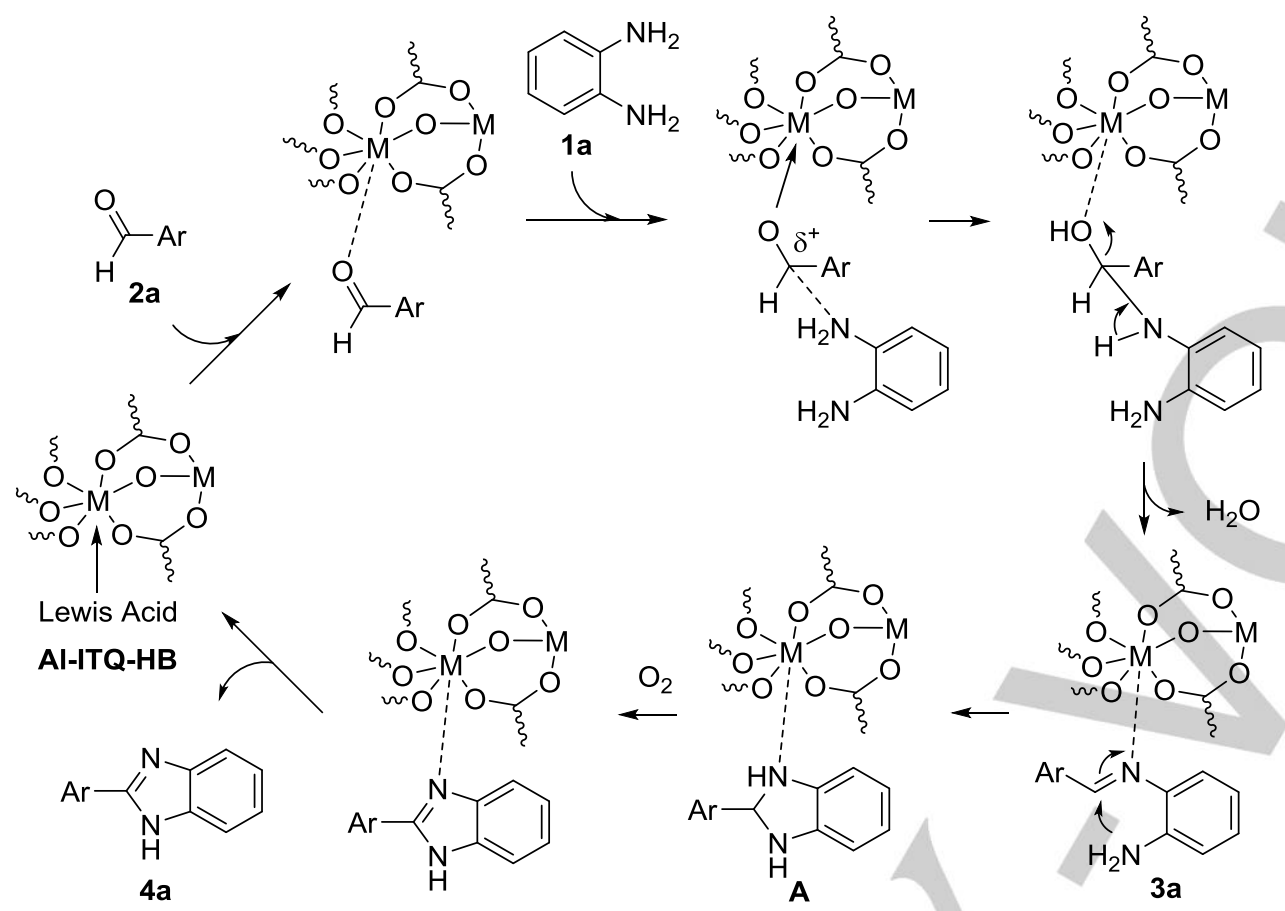

Scheme 1. Synthesis of benzimidazoles using o-diaminoarenes and aldehydes. Plausible mechanistic pathway.
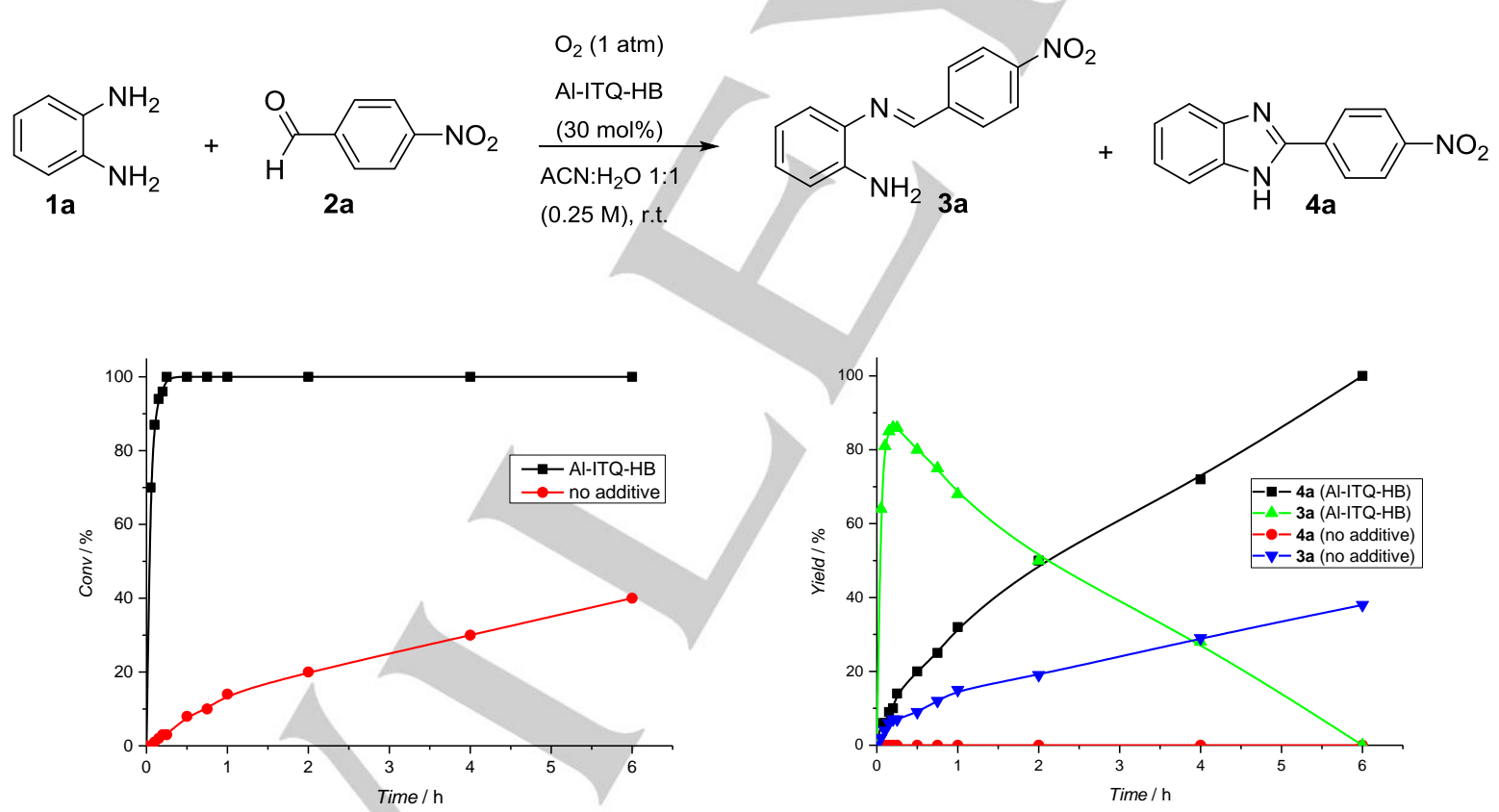

Scheme 2. Kinetic study of the synthesis of 2-substituted benzimidazole 4a using AI-ITQ-HB and control experiment.

The oxidative cyclization step was studied separately and product $3 a$ was independently prepared and isolated and treated under oxygen atmosphere in $\mathrm{ACN}: \mathrm{H}_{2} \mathrm{O}$ in the presence of a variety of additives (Table 2). Superiority of AI-ITQ-HB was also evident in this reaction step. While desired product 4 a was not formed in the absence of additives after 24 hours, AI-ITQ-HB (30 
mol\%) affords full conversion to benzimidazole $\mathbf{4 a}$ in 24 hours reaction time. The particular features of our supramolecular host are evidenced since the related MIL-53 $(\mathrm{Al})$ and $\mathrm{Al}(\mathrm{OH})(\mathrm{OAc})_{2}$ allow product formation in lower yield (14 and $31 \%$, respectively). The Brønsted acid 4-heptylbenzoic acid also catalyzed the transformation although at lower pace when compared to AlITQ-HB (Table 2, Entry 5). Furthermore, the use of the surfactant sodium 4-heptylbenzoate (as a related structural unit in Al-ITQ-HB) under otherwise identical conditions $\left(\mathrm{ACN}: \mathrm{H}_{2} \mathrm{O}\right)$ was not successful in this case in the oxidative cyclization of imine 3a (Table 2, Entry 6). We believe that $\mathrm{O}_{2}$ sorption ability along with the hydrophobic characteristics of Al-ITQ-HB facilitate the encounter of this two reagents and promote the transformation. Weak Lewis acids in the solid may also play a role, since we observe that in the one-pot procedure (Table 1, Entry 2) the benzimidazole $\mathbf{4 a}$ is formed in lower reaction time of 6 hours, while 24 hours were required to achieve full conversion when 3a was used as starting material in the cyclization step (Table 2, Entry 2).

To test the generality and versatility of this method, a series of aromatic aldehydes 2 was treated with various o-diaminoarenes 1 under optimal reaction conditions. The developed process was found to be excellent in terms of yield and selectivity resulting in a variety of 2-substituted benzimidazoles 4 in very high yield (Table 3). Apparently, the position of the substituents in the benzaldehyde ring did not have great influence on the reactivity

Table 2. Oxidative cyclization reaction of Shiff's base $\mathbf{3 a}$ to benzimidazole 4a by molecular oxygen as "green" oxidant. ${ }^{[a]}$

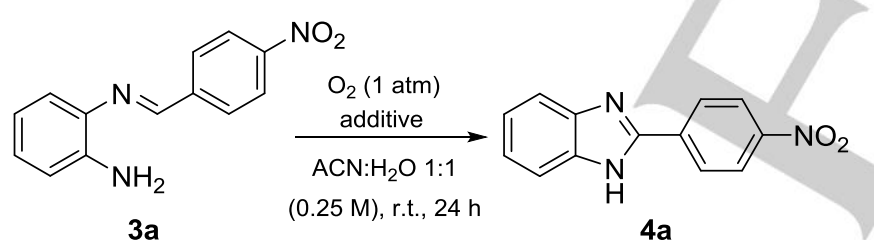

3a $(0.25 \mathrm{M})$, r.t., $24 \mathrm{~h}$

$4 a$

\begin{tabular}{lll}
\hline Entry & Additive $(\mathrm{X} \mathrm{mol} \%)$ & $\mathbf{4 a}^{[\mathrm{bb}}$ \\
\hline 1 & - & 0 \\
2 & Al-ITQ-HB (30) & 95 \\
3 & MIL-53 (Al) (30) & 14 \\
4 & Al(OH)(OAc) 2 (30) & 31 \\
5 & 4-heptylbenzoic acid (30) & 36 \\
6 & Na 4-heptylbenzoate (30) & 0 \\
\hline
\end{tabular}

[a] Reaction conditions: imine $3 a(0.1 \mathrm{mmol})$, and additive $(\mathrm{X} \mathrm{mol} \%)$ in ACN: $\mathrm{H}_{2} \mathrm{O} 1: 1(0.25 \mathrm{M})$ at room temperature under $\mathrm{O}_{2}$ atmosphere for 24 hours. [b] \% Yield determined by ${ }^{1} \mathrm{H}$ NMR using trimethoxybenzene as external standard. and selectivity (Table 3, entries 1-4). Similarly, no distinct substituent effect was observed on the yields of 2-substituted

Table 3. Selective synthesis of 2-arylbenzimidazoles in the presence of AlITQ-HB catalyst. ${ }^{[\mathrm{a}]}$

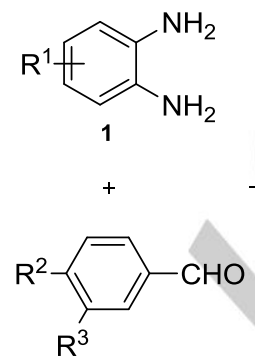

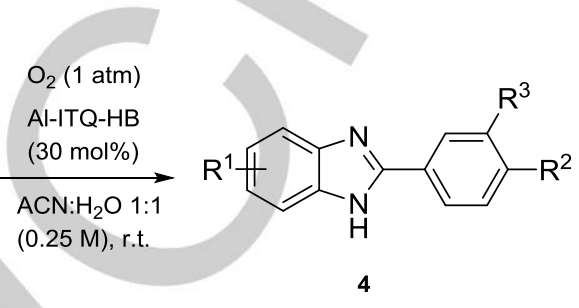

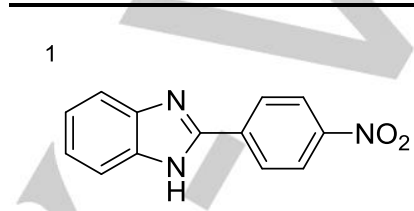

$0 \%$ Yield without Cat 95\% Yield with Al-ITQ-HB

$3^{c}$<smiles>c1ccc(-c2nc3ccccc3[nH]2)cc1</smiles>
4c $\left\{\begin{array}{l}37 \% \text { Yield without Cat } \\ 85 \% \text { Yield with AI-ITQ-HB }\end{array}\right.$<smiles></smiles>
4e $\left\{\begin{array}{c}0 \% \text { Yield without Cat } \\ 94 \% \text { Yield with Al-ITQ-HB }\end{array}\right.$

$7^{e}$

4g $\left\{\begin{array}{l}11 \% \text { Yield without Cat } \\ 70 \% \text { Yield wh }\end{array}\right.$ $\mathbf{4 g}\left\{\begin{array}{l}70 \% \text { Yield with AI-ITQ-HB } \\ \text { 7T }\end{array}\right.$<smiles>Cc1ccc(-c2nc3ccccc3[nH]2)cc1</smiles>

$2^{b}$<smiles>Clc1ccc(-c2nc3ccccc3[nH]2)cc1</smiles>
\{ $80 \%$ Yield with Al-ITQ-HB

$4^{d}$<smiles>O=[N+]([O-])c1cccc(-c2nc3ccccc3[nH]2)c1</smiles>

4d $\left\{\begin{array}{r}0 \% \text { Yield without Cat } \\ 93 \% \text { Yield with Al-ITQ- }\end{array}\right.$<smiles>Cc1cccc2[nH]c(-c3ccc([N+](=O)[O-])cc3)nc12</smiles>

4 f $\left\{\begin{array}{c}0 \% \text { Yield without Cat } \\ 91 \% \text { Yield with Al-ITQ }\end{array}\right.$

$8^{e}$<smiles>COc1ccc(-c2nc3ccccc3[nH]2)cc1</smiles>

4h $\left\{\begin{array}{l}8 \% \text { Yield without Cat } \\ \text { (n) }\end{array}\right.$ $\left\{\begin{array}{l}80 \% \text { Yield with AI-ITQ-HB } \\ \text { h }\end{array}\right.$ 4b $\{19 \%$ Yield without Cat

[a] Reaction conditions: o-phenylendiamine 1 (0.1 mmol), aldehyde 2 (0.1 $\mathrm{mmol})$ and catalyst $(30 \mathrm{~mol} \%)$ in $\mathrm{ACN}: \mathrm{H}_{2} \mathrm{O} 1: 1(0.25 \mathrm{M})$ at room temperature under $\mathrm{O}_{2}$ atmosphere for 6 hours. [b] 18 hours. [c] 12 hours. [d] 16 hours. [e] 24 hours. 
benzimidazoles 4 by varying substituents in the o-diaminoarene component (Table 3, entries 5-6). Aromatic aldehydes with electron donating groups while reacting with diminished selectivity, afford the benzimidazole product in good yields (Table 3, entries 7-8)

Another important aspect of heterogeneous catalysis concerns the stability of the catalyst during recycling runs. This is certainly an advantage with respect to homogeneous catalysis. In our case, the supramolecular catalyst Al-ITQ-HB, could be recovered by simple centrifugation or filtration and can be reused for further repeating runs (Supporting Information). A slight deterioration of the catalytic activity was observed, while good yields of the benzimidazole product 4 a $(93 \%$ and $91 \%$ in runs 2 and 3, respectively) were achieved by allowing longer reaction time (24 h). PXRD showed that the recycled AI-ITQ-HB maintain its mesoscopic nature after use being observable the low angle diffraction band (Supporting Information).

\section{Cyanosilylation reaction}

Encouraged by the excellent results and owing to the facility of Al-ITQ-HB in activating carbonyl compound derivatives in condensation reactions with o-phenylendiamines as shown above and with Meldrum's acid or malononitrile as reported previously, ${ }^{[9 a]}$ we wonder whether such carbonyl activation could be achieved in other non-condensation reactions and therefore versatility and potential of host AI-ITQ-HB should be expanded. We focused our attention to the cyanosilylation reaction of carbonyl compounds with trialkylsilyl cyanide since it is an important reaction in organic synthesis for producing cyanohydrin derivatives, which can be transformed into a variety of building blocks, including $\alpha$-hydroxy acids, $\alpha$-hydroxy ketones and $\beta$-amino alcohols. ${ }^{[39]}$

Indeed, many of the newly developed porous MOFs with open metal sites are tested as Lewis acid catalysts in the cyanosilylation of benzaldehydes using trimethylsilylcyanide (TMSCN). ${ }^{[38]}$ However, fewer reports account on the more difficult cyanosilylation of alkyl aldehydes and ketones, for which yields are normally lower than those of the cyanosilylation of benzaldehydes due to the lower activity and also steric hindrance in the case of ketones. Certainly, only a few heterogeneous catalysts have shown good conversions when ketones were used as substrates. ${ }^{[40]}$ Regarding to metal-organic materials, ${ }^{[41]}$ Table 4 shows a compilation of results attained in the cyanosilylation reaction of acetophenone as a model ketone substrate catalyzed by metal-organic solids. As observed, typical catalyst loadings ranges from 2 to $5 \mathrm{~mol} \%$ and sometimes relatively high temperature $\left(80^{\circ} \mathrm{C}\right)$, relatively high TMSCN:ketone ratio (up to 4 ) or the use of ultrasound is necessary to achieve efficient conversion for this particular

Table 4. Cyanosilylation reaction of acetophenone: a compilation of all reported procedures using metal-organic solids as heterogeneous catalysts

\begin{tabular}{|c|c|c|c|c|c|c|c|c|}
\hline Catalyst & $\begin{array}{l}\text { Catalyst } \\
\text { loading } \\
\text { [mol\%] }\end{array}$ & $\begin{array}{l}\text { TMSCN: } \\
\text { ketone ratio }\end{array}$ & solvent, $\mathrm{T}$ & $\mathrm{t}[\mathrm{h}]$ & $\mathrm{Y}[\%]^{[\mathrm{a}]}$ & $\mathrm{TON}^{[\mathrm{b}]}$ & TOF $\left[h^{-1}\right]^{[b]}$ & Ref \\
\hline $\mathbf{M n}_{3}\left[\left(\mathrm{Mn}_{4} \mathrm{Cl}\right)_{3}(\mathrm{BTT})_{8}\left(\mathrm{CH}_{3} \mathrm{OH}\right)_{10}\right]_{2}$ & 11 & $1.5: 1$ & $\mathrm{CH}_{2} \mathrm{Cl}_{2}$, r.t. & 24 & 28 & 2.5 & 0.1 & [41a] \\
\hline $\mathrm{Sc}_{2}$ (squarate) ${ }_{3}$ & 2 & $2.0: 1$ & $\mathrm{THF}, 40^{\circ} \mathrm{C}$ & 24 & 80 & 40 & 1.7 & [41b] \\
\hline$\left[\ln _{2}(\mathrm{dpa})_{3}(1,10 \text {-phen })_{2}\right] \cdot \mathrm{H}_{2} \mathrm{O}$ & 2.5 & $1.5: 1$ & solvent free, $80^{\circ} \mathrm{C}$ & 1 & 39 & 16 & 19 & {$[41 c]$} \\
\hline$\left[\ln _{4}(\mathrm{OH})_{4}(\text { hfipbb })_{4}\left(4,4^{\prime}-\right.\right.$-bipy $\left.)\right]$ & 2.5 & $1.1: 1$ & solvent free, $80^{\circ} \mathrm{C}$ & 48 & 99 & 40 & $140^{[\mathrm{c}]}$ & [41d] \\
\hline$\left[\ln _{8}(\mathrm{OH})_{6}(\text { popha })_{5}\left(\mathrm{H}_{2} \mathrm{O}\right)_{4}\right] \cdot 3 \mathrm{H}_{2} \mathrm{O}$ & 5 & $1.1: 1$ & solvent free, r.t. & 16 & 99 & 20 & 1.3 & [41e] \\
\hline$\left[\mathrm{Nd}(\mathrm{btc})\left(\mathrm{H}_{2} \mathrm{O}\right)\right] \cdot\left(\mathrm{H}_{2} \mathrm{O}\right)_{0.5} \mathrm{DMF}$ & 4.5 & $2.0: 1$ & solvent free, r.t. & 18 & 91 & 20 & 1.1 & {$[41 f]$} \\
\hline Er-DADQ & 2.5 & $2.0: 1$ & $\begin{array}{l}\text { solvent free, r.t. } \\
\text { ultrasound }\end{array}$ & 3 & 61 & 24 & 8 & [419] \\
\hline$\left[\mathrm{Ba}\left(\mathrm{H}_{2} \mathrm{~L}^{\mathrm{OMe}}\right)_{0.5}\right]$ & & $4.0: 1$ & solvent free, r.t. & 2 & 100 & 50 & 25 & {$[41 \mathrm{~h}]$} \\
\hline Al-ITQ-HB & 1 & $1.2: 1$ & solvent free, r.t. & 3 & 99 & 99 & $57^{[\mathrm{d}]}$ & this work \\
\hline Al-ITQ-HB & 0.5 & $1.2: 1$ & solvent free, r.t. & 8 & 97 & 194 & $56^{[\mathrm{d}]}$ & this work \\
\hline
\end{tabular}

[a] $Y=$ Yield. [b] Values calculated from the data reported in the reference. [c] Data reported in the reference. [d] Calculated at initial reaction rate as moles of product formed per hour and per mole of Lewis acidic active site. $\mathrm{H}_{3} \mathrm{BTT}=1,3,5$-benzenetristetrazol-5-yl; $\mathrm{H}_{2}$ dpa $=$ diphenic acid; 1,10-phen = 1,10-phenantroline; $\mathrm{H}_{2}$ hfipbb = 4,4'-hexaflurorisopropylidene bis(benzoic acid); 4,4'-bipy = 4,4'-bipyridine; $\mathrm{H}_{3}$ popha = 5-(4-carboxy-2nitrophenoxy)isophthalic acid. $\mathrm{H}_{3} \mathrm{BTC}=1,3,5$-benzenetricarboxylic acid. $\mathrm{H}_{2} \mathrm{DADQ}=\mathrm{N}, \mathrm{N}^{\prime}$-dibenzoic acid-2,3-diaminoquinoxaline. $\mathrm{H}_{4} \mathrm{~L}^{\mathrm{OMe}}=5,5^{\prime}$ (2,3,6,7-tetramethoxyanthracene-9,10-diyl)diisophthalic acid. 
substrate. We will show herein that Al-ITQ-HB is the most efficient metal-organic solid catalyst, as far as we know, for the cyanosilylation reaction of acetophenone. Low catalyst loading of $0.5 \mathrm{~mol} \%$ could be used to promote efficiently the transformation under very mild reactions conditions in short reaction time.

We used acetophenone as a model ketone substrate to investigate the effect of hydrophobic AI-ITQ-HB on the cyanosilylation reaction. Our experiments employed a 1:1.2 molar ratio of acetophenone and trimethylsilylcyanide (TMSCN) at ambient temperature and under solvent free conditions. It should be noted that no thermal pre-treatment was necessary in order to activate the hybrid metal-organic solid, or to remove adsorbed solvent species, and AI-ITQ-HB was used directly in the catalytic reaction. As shown in Scheme 3, a loading of as low as $0.5 \mathrm{~mol} \%$ was sufficient in promoting the reaction efficiently, while in the absence of Al-ITQ-HB, the desired product was not formed.

Once again, the particular features of Al-ITQ-HB probed crucial in the catalytic procedure, since the related MOF MIL-53 (Al) with similar Lewis acidic sites, did not promote the transformation under otherwise equal conditions (solvent free conditions using 1:1.2 molar ratio of acetophenone and trimethylsilylcyanide at ambient temperature). The hydrophobic cavity of Al-ITQ-HB appears to play a significant role in the reaction because the individual components ${ }^{[38]} \mathrm{Al}(\mathrm{OH})(\mathrm{OAc})_{2}$ or 4-heptylbenzoic acid did not promote the transformation substantially (Scheme 3).

When using a solid catalyst two points become important issues to be considered. The first one is the possibility that some active sites migrate from the solid to the liquid phase and that those leached species would become responsible for a significant extent of the catalytic activity. To rule out the contribution of homogeneous catalysis in the results shown in Scheme 3, the reaction was carried out in the presence of the solid AI-ITQ-HB for $1 \mathrm{~h}$ and, at that point, the catalyst was filtered off. The liquid filtrate was then allowed to react, but no significant conversion was observed after 7 hours under the presented reaction conditions (Supporting Information). This clearly indicates that no active species were present in the liquid phase and it is a true heterogeneously catalyzed procedure. The second point is the deactivation and reusability of Al-ITQ-HB. It should be noted that while most supramolecular systems and Lewis acids are difficult to recover or they decompose or deactivate in the presence of protic solvents or water, Al-ITQ-HB is stable both in water and organic solvents and could be easily recovered and reused for at least 8 runs without loss of yield of product. Thus, after the first run, which gave the corresponding cyanosilyl ether in $98 \%$ yield after 2 hours when using 2 mol\% loading of Al-ITQ-HB, the catalyst was filtered and washed with $\mathrm{MeOH}$ and dried in vacuum for two hours before submitting it to the next run. The resulting recovered catalyst was weighed and the next reaction was run using amounts of reactants to maintain the same substrate/catalyst ratio (Scheme 4). The average chemical yield for 8 consecutive runs was $97 \%$ that account for a TON of 388 , which clearly demonstrates the practical recyclability of this catalyst. Furthermore, the low-angle XRD pattern of the

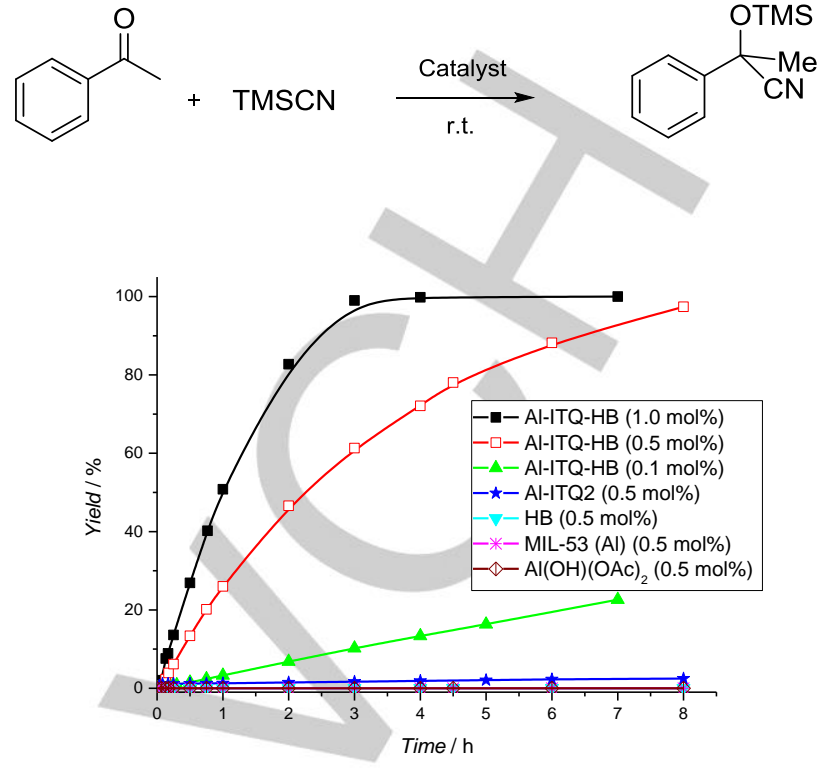

Scheme 3. Cyanosilylation reaction of acetophenone with trimethylsilylcyanide

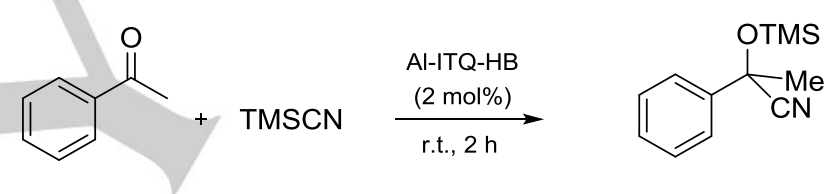

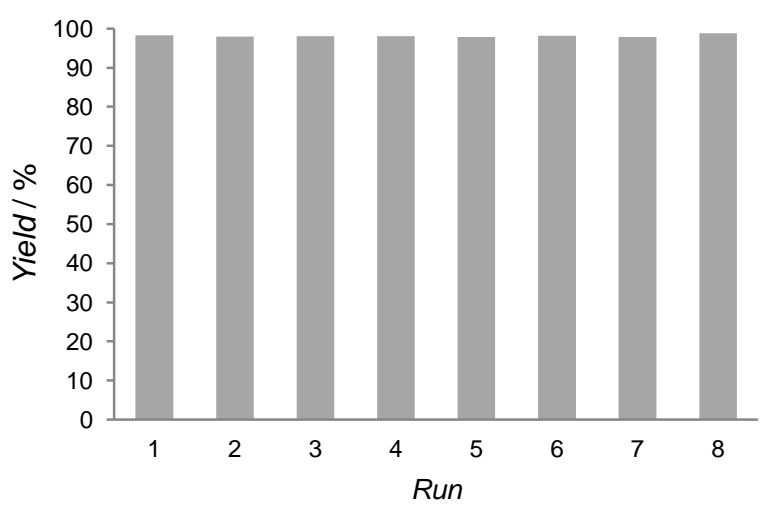

Scheme 4. Recyclability of AI-ITQ-HB for the cyanosilylation of acetophenone using TMSCN.

mesoscopic hybrid material, Al-ITQ-HB was measured after the $8^{\text {th }}$ run and the trace resulted similar to that of the as synthesized material (Supporting Information). Further characterization of the reutilized material was performed (Supporting Information) such as FTIR spectroscopy analysis and termogravimetrical analysis and the data showcase the chemical stability of Al-ITQ-HB under the reaction conditions. 
<smiles>CC(=O)c1ccc2cc(C(C)=O)ccc2c1</smiles>

6
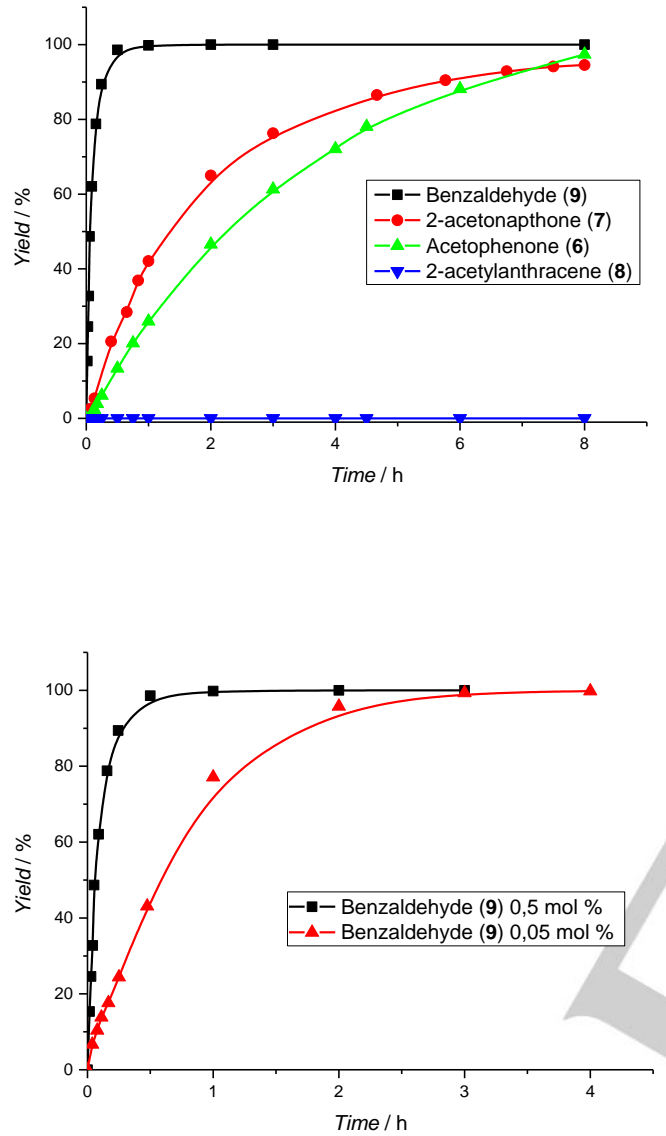

Scheme 5. Cyanosilylation reaction of ketones and bezaldehyde with trimethylsilylcyanide at room temperature in the presence of Al-ITQ-HB catalyst $(0.5 \mathrm{~mol} \%)$ under solvent-free reaction conditions.

The scope in the cyanosilylation reaction was assayed for several ketones of increased size to establish whether the solid could display a size exclusion effect (Scheme 5). Indeed, while 2-acetonapthone 7 gave the corresponding TMS-cyanohydrine product with a reaction rate slightly higher than acetophenone 6 (Scheme 5), we observed that 2-acetylanthracene hardly forms the desired product under the same reaction conditions $(0.5$ mol\% of Al-ITQ-HB was used). However, the observed different behavior have to be also attributed to the inherent distinct reactivity of the substrates. Performance with aldehydes was also evaluated by using the model substrate benzaldehyde. As expected, reaction rate was much higher than for ketones (Scheme 5) and catalyst loading could be reduced to even 0.05 mol\% to achieve efficiently the desired TMS-cyanhydrine product.

\section{Conclusions}

In summary, Al-ITQ-HB, which can be prepared by one single operation from commercially available and cheap starting materials, efficiently catalyzes the synthesis of benzimidazoles and the cyanosilylation reaction of carbonyl compounds. The catalyst shows chemical stability and could be recovered and reused for several reaction cycles without loss of reactivity. These results clearly exhibit the promising abilities of supramolecular metal-organic Al-ITQ-HB as catalyst in organic synthesis, especially for fine chemicals synthesis. The effective combination of both the weak Lewis acids and the hydrophobic pockets in the solid can be responsible for the excellent catalytic activity.

\section{Experimental Section}

General Procedure for the synthesis of benzimidazoles.

Al-ITQ-HB (8.0 mg, $0.03 \mathrm{mmol}, 30 \mathrm{~mol} \%$ ) was placed in a $2 \mathrm{~mL}$ glass vessel. Diamine $(0.1 \mathrm{mmol})$ and aldehyde $(0.1 \mathrm{mmol})$ were then added The vessel was sealed and purged with $\mathrm{O}_{2}$ balloon (1 atm). Acetonitrile $(0.2 \mathrm{~mL})$ and water $(0.2 \mathrm{~mL})$ were then added and the mixture was left to stir vigorously at room temperature for the corresponding time. The reaction mixture was then extracted with ethyl acetate. Solvent was later removed under reduced pressure and the crude product was purified by column chromatography using hexane/ethyl acetate as eluent.

\section{General Procedure for the cyanosilylation of ketones.}

The mesoscopic hybrid material, AI-ITQ-HB (0.025 mmol, $0.5 \mathrm{~mol} \%)$ was placed in a $10 \mathrm{~mL}$ glass vessel. Ketone (5.08 mmol), TMSCN (6.10 $\mathrm{mmol})$ and dodecane $(0.43 \mathrm{mmol})$ were then added. The mixture was left to stir vigorously at room temperature. Yield was determined by analysis by gas chromatography of aliquots taken from the reaction mixture at different times.

\section{Acknowledgements ((optional))}

This work was funded by the Generalitat Valenciana (Prometeo). The Severo Ochoa program (SEV-2012-0267) is thankfully acknowledged. S. R-B acknowledges a PhD fellowship from the Generalitat Valenciana.

Keywords: supramolecular catalyst $\cdot$ metal-organic catalyst • enzyme mimic $\cdot$ benzimidazole $\cdot$ cyanosilylation

[1] C. J. Brown, F. D. Toste, R. G. Bergman, K. N. Raymond, Chem. Rev. 2015, 115, 3012-3035

[2] a) H. Li, F. Li, B. Zhang, X. Zhou, F. Yu, L. Sun, J. Am. Chem. Soc 2015, 137, 4332-4335; b) F. Hapiot, H. Bricout, S. Menuel, S. Tilloy, E. Monflier, Catal. Sci. Technol. 2014, 4, 1899-1908; c) A. Harada, Y. Takashima, M. Nakahata, Acc. Chem. Res. 2014, 47, 2128-2140. 
[3] a) H. Cong, Z.-J. Li, Y.-H. Wang, Z. Tao, T. Yamato, S.-F. Xue, G. Wei, J. Mol. Catal. A: Chem. 2013, 374-375, 32-38; b) E. Masson, X. Ling, R. Joseph, L. Kyeremeh-Mensah, X. Lu, RSC Adv. 2012, 2, 1213-1247.

[4] a) J.-N. Rebilly, O. Reinaud, Supramol. Chem. 2014, 26, 454-479; b) M. Durmaz, A. Sirit, Supramol. Chem. 2013, 25, 292-301.

[5] D. Ajami, L. Liu, J. Rebek, Jr., Chem. Soc. Rev. 2015, 44, 490-499.

[6] A. Corma, H. Garcia, Eur. J. Inorg. Chem. 2004, 1143-1164.

[7] M. Yoshizawa, J. K. Klosterman, M. Fujita, Angew. Chem. Int. Ed. 2009 48, 3418-3438.

[8] M. Yoshizawa, M. Tamura, M. Fujita, Science 2006, 312, 251-254.

[9] a) P. Garcia-Garcia, J. M. Moreno, U. Diaz, M. Bruix, A. Corma, Nat Commun 2016, 7:10835; b) J. M. Moreno, I. Navarro, U. Díaz, J. Primo, A. Corma, Angew. Chem. Int. Ed. 2016, 55, 11026-11030.

[10] a) B. Santanu, C. Padmaparna, Curr. Med. Chem. 2008, 15, 1762 1777; b) K. McKeage, S. K. A. Blick, J. D. Croxtall, K. A. LysengWilliamson, G. M. Keating, Drugs 2008, 68, 1571-1607; c) R. O. McCracken, K. B. Lipkowitz, J. Parasitol. 1990, 76, 180-185; d) J. Garcia-Quiroz, J. Camacho, Anti-Cancer Agents Med. Chem. 2011, 11, 307-314.

[11] a) A. R. Porcari, R. V. Devivar, L. S. Kucera, J. C. Drach, L. B. Townsend, J. Med. Chem. 1998, 41, 1252-1262; b) M. T. Migawa, J.-L. Girardet, J. A. Walker, G. W. Koszalka, S. D. Chamberlain, J. C. Drach, L. B. Townsend, J. Med. Chem. 1998, 41, 1242-1251; c) J. Mann, A. Baron, Y. Opoku-Boahen, E. Johansson, G. Parkinson, L. R. Kelland, S. Neidle, J. Med. Chem. 2001, 44, 138-144.

[12] J. Weber, ChemSusChem 2010, 3, 181-187

[13] a) Y. Wang, K. Sarris, D. R. Sauer, S. W. Djuric, Tetrahedron Lett. 2006 47, 4823-4826; b) S.-Y. Lin, Y. Isome, E. Stewart, J.-F. Liu, D. Yohannes, L. Yu, Tetrahedron Lett. 2006, 47, 2883-2886; c) R. N Nadaf, S. A. Siddiqui, T. Daniel, R. J. Lahoti, K. V. Srinivasan, J. Mol. Catal. A: Chem. 2004, 214, 155-160.

[14] P. N. Preston, Editor, The Chemistry of Heterocyclic Compounds, Vol. 40: Benzimidazoles and Congeneric Tricyclic Compounds, Pt. 2, John Wiley and Sons, 1980

[15] R. Trivedi, S. K. De, R. A. Gibbs, J. Mol. Catal. A: Chem. 2006, 245, 8 11.

[16] K. Nagata, T. Itoh, H. Ishikawa, A. Ohsawa, Heterocycles 2003, 61, 9396.

[17] M. Curini, F. Epifano, F. Montanari, O. Rosati, S. Taccone, Synlett 2004, 1832-1834.

[18] A. V. Narsaiah, A. R. Reddy, J. S. Yadav, Synth. Commun. 2011, 41, 262-267.

[19] R. V. Shingalapur, K. M. Hosamani, Catal. Lett. 2010, 137, 63-68.

[20] K. Bahrami, M. M. Khodaei, I. Kavianinia, J. Chem. Res. 2006, 783-784.

[21] B. Yadagiri, J. W. Lown, Synth. Commun. 1990, 20, 955-963.

[22] E. Verner, B. A. Katz, J. R. Spencer, D. Allen, J. Hataye, W. Hruzewicz, H. C. Hui, A. Kolesnikov, Y. Li, C. Luong, A. Martelli, K. Radika, R. Rai, M. She, W. Shrader, P. A. Sprengeler, S. Trapp, J. Wang, W. B. Young R. L. Mackman, J. Med. Chem. 2001, 44, 2753-2771.

[23] J. J. Vanden Eynde, F. Delfosse, P. Lor, Y. Van Haverbeke, Tetrahedron 1995, 51, 5813-5818.

[24] H. Chikashita, S. Nishida, M. Miyazaki, Y. Morita, K. Itoh, Bull. Chem. Soc. Jpn. 1987, 60, 737-746.
[25] F. Paetzold, F. Zeuner, T. Heyer, H. J. Niclas, Synth. Commun. 1992, 22, 281-288.

[26] I. Bhatnagar, M. V. George, Tetrahedron 1968, 24, 1293-1298.

[27] F. F. Stephens, J. D. Bower, J. Chem. Soc. 1949, 2971-2972.

[28] J. R. Gillard, P. L. Beaulieu, Org. Synth. 2012, 89, 131-142.

[29] M. A. Weidner-Wells, K. A. Ohemeng, V. N. Nguyen, S. Fraga-Spano, M. J. Macielag, H. M. Werblood, B. D. Foleno, G. C. Webb, J. F. Barrett, D. J. Hlasta, Bioorg. Med. Chem. Lett. 2001, 11, 1545-1548.

[30] P. Gogoi, D. Konwar, Tetrahedron Lett. 2006, 47, 79-82.

[31] M. Chakrabarty, S. Karmakar, A. Mukherji, S. Arima, Y. Harigaya, Heterocycles 2006, 68, 967-974.

[32] L.-H. Du, Y.-G. Wang, Synthesis 2007, 675-678.

[33] R. L. Lombardy, F. A. Tanious, K. Ramachandran, R. R. Tidwell, W. D. Wilson, J. Med. Chem. 1996, 39, 1452-1462.

[34] a) K. Bahrami, M. M. Khodaei, A. Nejati, Green Chem. 2010, 12, 1237 1241; b) P. Ghosh, A. Mandal, Catal. Commun. 2011, 12, 744-747.

[35] V. Kumar, D. G. Khandare, A. Chatterjee, M. Banerjee, Tetrahedron Lett. 2013, 54, 5505-5509.

[36] T. Loiseau, C. Serre, C. Huguenard, G. Fink, F. Taulelle, M. Henry, T. Bataille, G. Férey, Chem. Eur. J. 2004, 10, 1373-1382.

[37] P. Rallapalli, K. P. Prasanth, D. Patil, R. S. Somani, R. V. Jasra, H. C. Bajaj, J. Porous Mater. 2011, 18, 205-210.

[38] P. Garcia-Garcia, M. Muller, A. Corma, Chem. Sci. 2014, 5, 2979-3007.

[39] a) R. J. H. Gregory, Chem. Rev. 1999, 99, 3649-3682; b) M. North Tetrahedron-Asymmetry 2003, 14, 147-176

[40] a) M. Curini, F. Epifano, M. C. Marcotullio, O. Rosati, M. Rossi, Synlett 1999, 315-316; b) H. Firouzabadi, N. Iranpoor, A. A. Jafari, J. Organomet. Chem. 2005, 690, 1556-1559; c) K. Yamaguchi, T. Imago, Y. Ogasawara, J. Kasai, M. Kotani, N. Mizuno, Adv. Synth. Catal. 2006 348, 1516-1520; d) K. Iwanami, J.-C. Choi, B. Lu, T. Sakakura, H. Yasuda, Chem. Commun. 2008, 1002-1004; e) Y. Ogasawara, S Uchida, K. Yamaguchi, N. Mizuno, Chem. Eur. J. 2009, 15, 4343-4349; f) Y. Teng, P. H. Toy, Synlett 2011, 551-554; g) Y. Jia, S. Zhao, Y.-F. Song, Appl. Catal., A 2014, 487, 172-180; h) S. Martin, R. Porcar, E. Peris, M. I. Burguete, E. Garcia-Verdugo, S. V. Luis, Green Chem 2014, 16, 1639-1647; i) B. M. Choudary, N. Narender, V. Bhuma, Synth. Commun. 1995, 25, 2829-2836; j) J. Wang, Y. Masui, K. Watanabe, M. Onaka, Adv. Synth. Catal. 2009, 351, 553-557; k) M. Tan, Y. Zhang, J. Y. Ying, Adv. Synth. Catal. 2009, 351, 1390-1394; I) Y. Izumi, M. Onaka, J. Mol. Catal. 1992, 74, 35-42.

[41] a) S. Horike, M. Dincă, K. Tamaki, J. R. Long, J. Am. Chem. Soc. 2008 130, 5854-5855; b) F. Gandara, B. Gomez-Lor, M. Iglesias, N. Snejko, E. Gutierrez-Puebla, A. Monge, Chem. Commun. 2009, 2393-2395; c) L. M. Aguirre-Diaz, M. Iglesias, N. Snejko, E. Gutierrez-Puebla, M. A. Monge, CrystEngComm 2013, 15, 9562-9571; d) L. M. Aguirre-Diaz, M. Iglesias, N. Snejko, E. Gutierrez-Puebla, M. A. Monge, RSC Adv. 2015, 5, 7058-7065; e) L. M. Aguirre-Diaz, M. Iglesias, N. Snejko, E. Gutierrez-Puebla, M. A. Monge, Chem. Eur. J. 2016, 22, 6654-6665; f) M. Gustafsson, A. Bartoszewicz, B. Martín-Matute, J. Sun, J. Grins, T. Zhao, Z. Li, G. Zhu, X. Zou, Chem. Mater. 2010, 22, 3316-3322; g) Y. Zhu, Y. Wang, P. Liu, C. Xia, Y. Wu, X. Lu, J. Xie, Dalton T. 2015, 44, 1955-1961; h) F. Liu, Y. Xu, L. Zhao, L. Zhang, W. Guo, R. Wang, D. Sun, J. Mater. Chem. A 2015, 3, 21545-21552. 
Entry for the Table of Contents (Please choose one layout)

Layout 1:

\section{FULL PAPER}

A metal-organic hybrid material catalyzes the cyanosilylation reaction of ketones and the synthesis of benzimidazoles. The catalytic reactions require both the supramolecular microenvironment catalyst and the Lewis acidity operating in concert to achieve efficient turnover number/frequency. The supramolecular catalyst acts as functional enzyme mimic and the catalytic solid could be recycled and reused.

Layout 2:

\section{FULL PAPER}

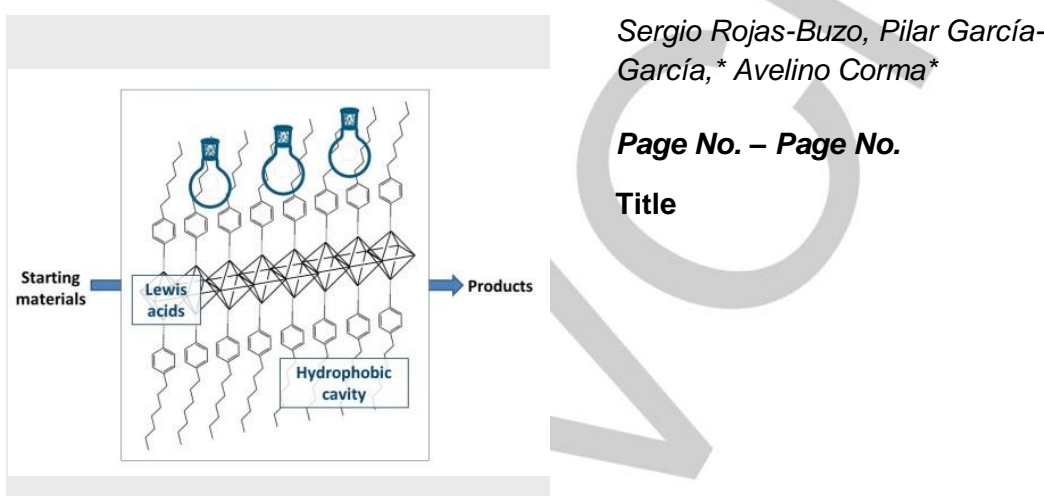

Sergio Rojas-Buzo, Pilar García-

Page No. - Page No.

Title

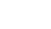

((Insert TOC Graphic here; max. width: $11.5 \mathrm{~cm}$; max. height: $2.5 \mathrm{~cm})$ )
Author(s), Corresponding Author(s)*

Page No. - Page No.

Title

Text for Table of Contents 